\title{
Extended sternoclavicular joint infections in cirrhotic patients: staged interdisciplinary approach with thoracic and plastic surgery
}

\author{
Waldemar Schreiner ${ }^{1}$, Wojciech Dudek ${ }^{1}$, Denis lulian Trufa ${ }^{1}$, Raymund E. Horch $^{2}$, Horia Sirbu ${ }^{1}$ \\ 'Department of Thoracic Surgery, University Hospital Erlangen, Friedrich-Alexander-University Erlangen-Nuremberg, Erlangen 91054, \\ Germany. \\ ${ }^{2}$ Department of Plastic and Hand Surgery, University Hospital Erlangen, Friedrich-Alexander-University Erlangen-Nuremberg, Erlangen
} 91054, Germany.

Correspondence to: Dr. Waldemar Schreiner, Department of Thoracic Surgery, University hospital Erlangen, Friedrich-AlexanderUniversity Erlangen-Nuremberg, Krankenhausstrasse 12, Erlangen 91054, Germany. E-mail: waldemar.schreiner@uk-erlangen.de

How to cite this article: Schreiner W, Dudek W, Trufa DI, Horch RE, Sirbu H. Extended sternoclavicular joint infections in cirrhotic patients: staged interdisciplinary approach with thoracic and plastic surgery. Plast Aesthet Res 2018;5:32.

http://dx.doi.org/10.20517/2347-9264.2018.45

Received: 11 Jun 2018 First Decision: 23 Jul 2018 Revised: 30 Jul 2018 Accepted: 30 Jul 2018 Published: 29 Aug 2018

Science Editor: Raymund Engelbert Horch Copy Editor: Cai-Hong Wang Production Editor: Huan-Liang Wu

\begin{abstract}
Aim: Sternoclavicular joint infection associated with liver cirrhosis is an uncommon condition and the optimal surgical treatment is undefined.

Methods: Patients and methods: we retrospectively analysed data from six patients with sternoclavicular joint infections and liver cirrhosis underwent between February 2008 and May 2018 a staged therapy using negative pressure therapy followed by secondary "en bloc" joint resection and a pectoralis muscle flap (PMF) obliteration of the thoracic wall defect.
\end{abstract}

Results: Four patients successfully underwent a transfer of the PMF. The surgical revision was required for relevant bleeding in one and a tracheostomy was performed due to the prolonged intubation in another case. One patient died on the fifth day after surgery due to a cerebral septic embolic ischemia and aortic endocarditis.

Conclusion: The presence of liver insufficiency and coagulopathy was associated with an extensive blood product demand and required a well-balanced interdisciplinary management. During the follow-up only a minimal restriction in the shoulder mobility was observed.

Keywords: Liver cirrhosis, negative pressure therapy, pectoralis muscle flap, sternoclavicular joint infection

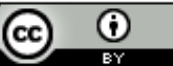

(C) The Author(s) 2018. Open Access This article is licensed under a Creative Commons Attribution 4.0 International License (https://creativecommons.org/licenses/by/4.0/), which permits unrestricted use, sharing, adaptation, distribution and reproduction in any medium or format, for any purpose, even commercially, as long as you give appropriate credit to the original author(s) and the source, provide a link to the Creative Commons license, and indicate if changes were made. 


\section{INTRODUCTION}

Sternoclavicular joint (SCJ) infections represent $1 \%$ of all septic joints in the general population and less than $4 \%$ of them occur in patients with liver cirrhosis ${ }^{[1]}$. The surgical treatment ranges from simple joint incision and drainage to radical joint resection. However, there are no clearly defined surgical principles of the SCJ infections management. The liver cirrhosis has been identified as a risk factor for severe SCJ infections that significantly increases perioperative mortality ${ }^{[2]}$. Therefore, in patients with liver insufficiency, the choice of the surgery must be adjusted to the reduced patient condition, expected higher perioperative morbidity and advanced stage of the disease. However, it should consequently follow the principles of the septic surgery. We present our multidisciplinary experience with the staged surgical management of severe SCJ in high-risk patients, performed by the thoracic and plastic-reconstructive surgeons.

\section{METHODS}

From February 2008 to May 2018 six patients with liver insufficiency were admitted to our hospital due to SCJ infections manifested by erythema and swelling over the SCJ area as well as shoulder pain aggravated by movement. Initial diagnostics included the joint aspiration, chest and neck computed tomography (CT) and standard blood tests. The first stage surgery included a J-shaped incision from the medial supraclavicular region, through the SCJ, to the median sternal line at the level of the second intercostal space. After extended debridement and necrectomy the negative pressure therapy (NPT) was started with $75 \mathrm{mmHg}$ and gradually increased to $125 \mathrm{mmHg}$. During subsequent operations, the bone viability and the extent of osteomyelitis were assessed and tissue biopsies for microbiological analysis were taken regularly until definitive wound closure. The intravenous antibiotic therapy was commenced due to the general anaesthesiology after taking the blood culture probes, modified according to the antibiogram and continued for 4 weeks after the hospital discharge.

Thanks to thoracic surgeons, "en bloc" resection of the SCJ including the hemi-manubrium, the middle $1 / 3$ of the clavicle as well as affected first and/or second rib was performed. Thereafter the NPT was continued for 2-3 weeks and the vacuum system exchanged every 3-5 days until wound granulation of tissue was formed. Afterwards, the chest wall defects were covered due to the plastic surgeons with the pedicled muscle or musculocutaneous flap involving chest wall musculature from the contralateral side [Figure 1].

\section{RESULTS}

The patient characteristics and clinical features are summarized in Table 1. All 6 patients were male at the age of $58 \pm 10$ years [range 45-72] suffering from alcohol related Child B or Child C liver cirrhosis with the median model of end stage liver disease score of 11.5 [range 9-16 ${ }^{[3]}$. The chest-CT showed the destruction of the SCJ and the neighbouring ribs with the soft tissue gangrene in 5 patients, and the chest wall abscess in all patients. Inflammatory mediastinal mass and chest wall phlegmon was noted in 4 and 3 patients, respectively. Osteomyelitis was histologically proven in all patients [Figure 2]. According to the SCJI classification of Abu Arab et al. ${ }^{[4]}$, grade IV and V extent was noted in 2 and 4 patients, respectively. One patient died on the 5th postoperative day due to cerebral septic embolism and aortic endocarditis. Four patients underwent successful chest wall defect coverage with the contralateral PMF [Figure 3], in 1 patient delayed wound closure was possible without PMF transposition. The surgical revision was necessary in 1 patient due to severe bleeding and 1 patient required tracheotomy for prolonged ventilation case. The intraoperative blood loss at the initial operation was $350 \pm 180 \mathrm{~mL}$. During the postoperative course $18 \pm 14.8$ erythrocyte concentrates, $16.3 \pm 18.1$ fresh frozen plasma concentrates and $1.5 \pm 0.7$ thrombocyte concentrates were transfused. The average NPT duration was $22 \pm 9$ days and the average length of hospital stay was $35 \pm 21$ days. The average follow-up time and disease-free interval were in 5 survivors $24 \pm 18$ months. 

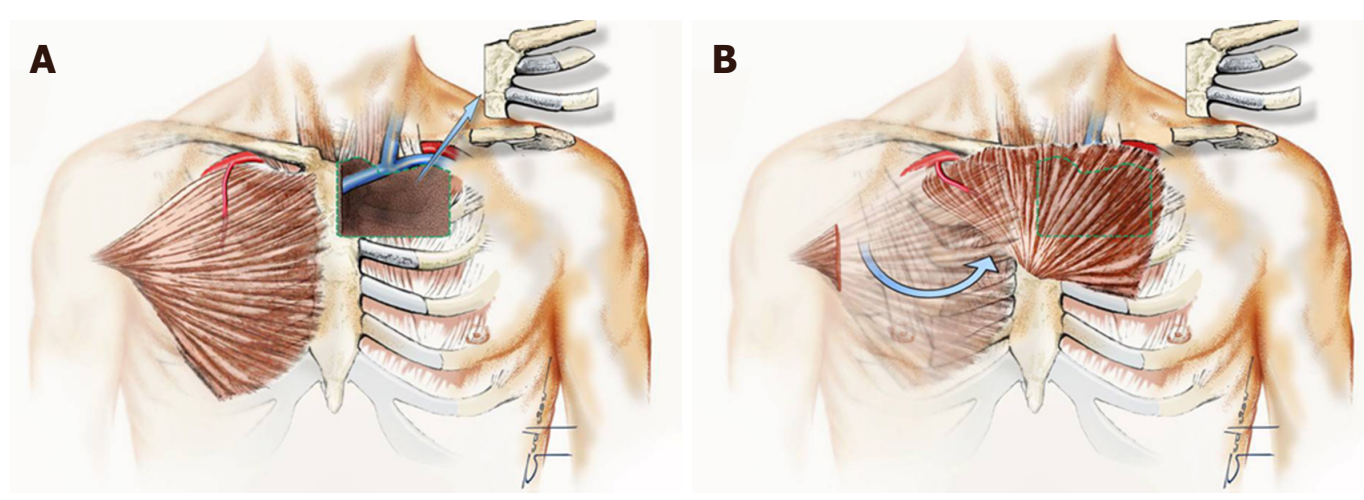

Figure 1. A: The scheme of "en bloc" SCJ resection involving the median third of clavicle; B: first and second rib and partial resection of manubrium combined with defect closure by contralateral pectoral muscle flap. SCJ: sternoclavicular joint
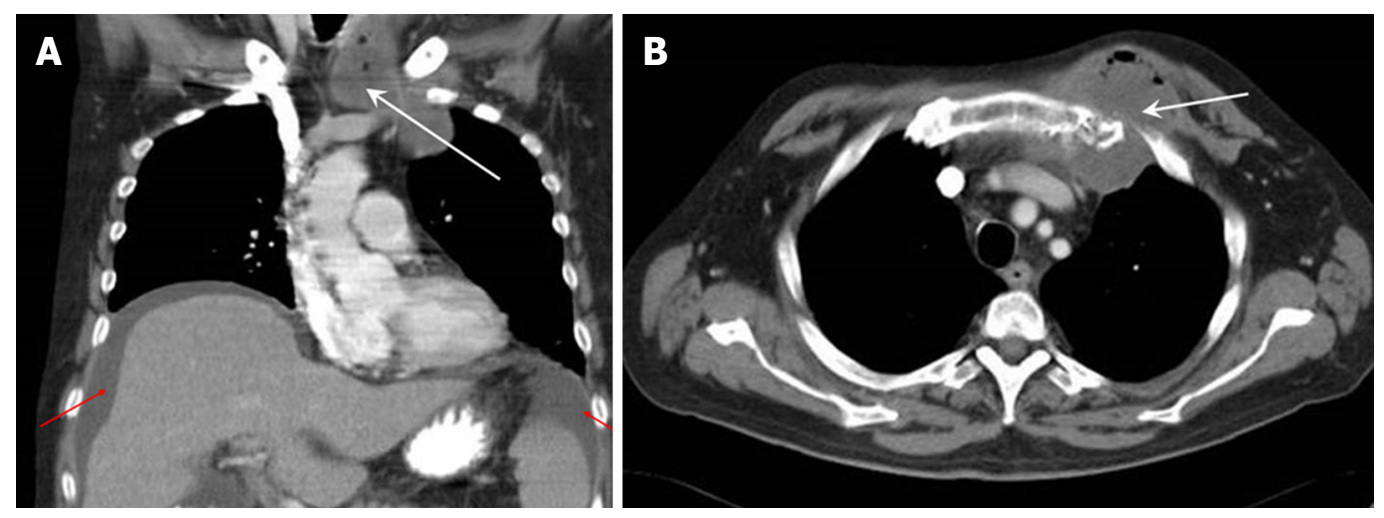

Figure 2. Rib osteolysis and mediastinitis extending to the neck on computed tomography scan (white arrow) and ascites according to liver insufficiency (red arrows)
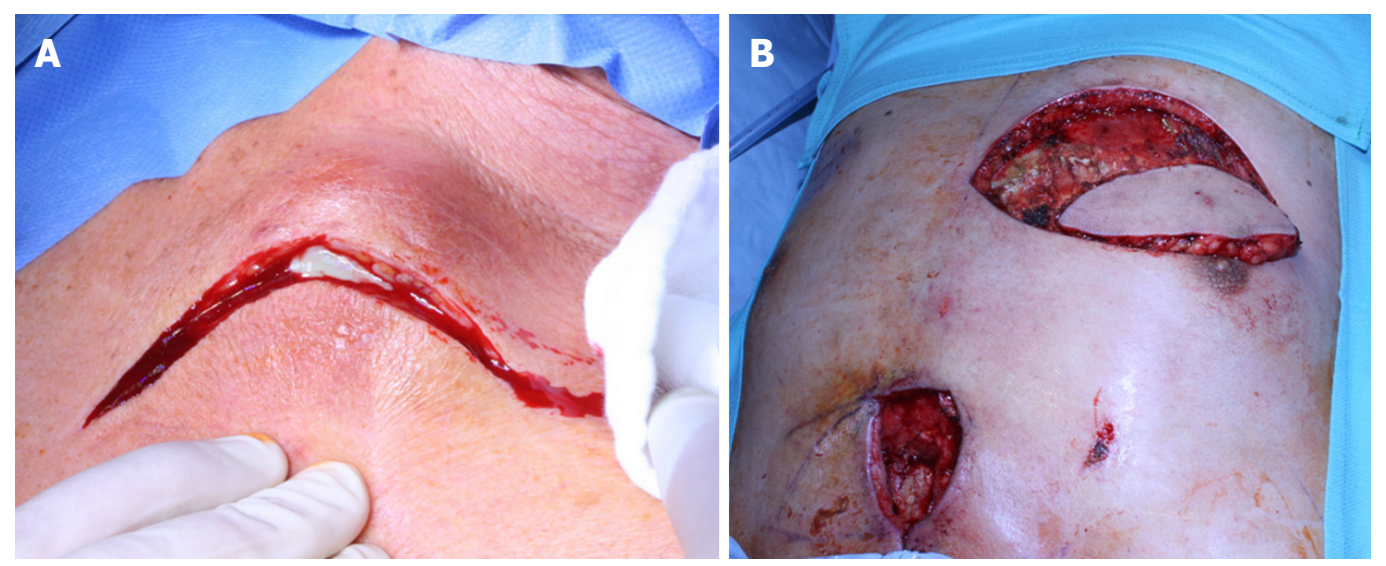

Figure 3. A: "J-shape" incision over sternal notch for extended debridement and necrectomy; B: well granulated wound after NPT in the left sternoclavicular joint and delayed defect closure with contralateral pectoral muscle flap. NPT: negative pressure therapy

\section{DISCUSSION}

There is only a little published evidence on SCJ infection in association with the liver insufficiency. Only one study and a case report describing in total 6 cirrhotic patients managed with open drainage and a packing are available to date ${ }^{[2,5]}$. The SCJ infections in the cirrhotic patients are debilitating and associated with surgical morbidity rate of up to $40 \%{ }^{[5]}$. Compromised immunity in the liver cirrhotic patients contributes to 
Table 1. Perioperative patient characteristics

\begin{tabular}{|c|c|c|c|c|c|c|c|c|c|c|c|}
\hline Pat. & Age & Sex & $\begin{array}{l}\text { Child class } \\
\text { of cirrhosis }\end{array}$ & $\begin{array}{l}\text { MELD- } \\
\text { score } \\
\text { (points) }\end{array}$ & $\begin{array}{c}\begin{array}{c}\text { Bact. cul- } \\
\text { tures }\end{array} \\
\text { Before NPT }\end{array}$ & $\begin{array}{c}\text { NPT } \\
\text { duration } \\
\text { (day) }\end{array}$ & $\begin{array}{c}\text { Bact. cul- } \\
\text { tures after } \\
\text { NPT }\end{array}$ & PMF & Complications & $\begin{array}{l}\text { 30-day } \\
\text { mortality }\end{array}$ & $\begin{array}{c}\text { Follow } \\
\text { up }\end{array}$ \\
\hline 1 & 58 & $M$ & Child C & 12 & E. coli & 22 & No & Yes & $\begin{array}{l}\text { Revision for } \\
\text { bleeding }\end{array}$ & No & 43 \\
\hline 2 & 68 & M & Child C & 7 & E. coli & 3 & E. coli & No & $\begin{array}{l}\text { Septic cerebral } \\
\text { embolism }\end{array}$ & Yes & \\
\hline 3 & 50 & M & Child B & 10 & Staph. aureus & 24 & No & No & & No & 32 \\
\hline 4 & 45 & M & Child B & 9 & E. coli & 32 & No & Yes & $\begin{array}{l}\text { Respiratory } \\
\text { insufficiency and } \\
\text { tracheostomy }\end{array}$ & No & 30 \\
\hline 5 & 58 & M & Child B & 15 & $\begin{array}{l}\text { Streptococcus } \\
\text { pneumoniae }\end{array}$ & 25 & No & Yes & & No & 36 \\
\hline 6 & 72 & M & Child C & 16 & Staph. aureus & 24 & No & Yes & & No & 2 \\
\hline
\end{tabular}

MELD: model of end stage liver disease; NPT: negative pressure therapy; PMF: pectoralis muscle flap

the extensive spread of infection to the surrounding mediastinal structures at the time of diagnosis, which is usually delayed ${ }^{[2,5]}$. There is no standardized treatment strategy for septic SCJ arthritis. Various surgical options including intravenous antibiotic therapy, SCJ incision with open drainage and secondary wound healing, radical joint resection with or without NPT combined with muscle flap transposition have been reported. The open drainage requires prolonged wound care up to 3 months and is associated with the failure rate of up to $80 \%{ }^{[6]}$. Therefore, simple incision and drainage appears insufficient in those patients with a severe septic arthritis, sternal and clavicular osteomyelitis with mediastinal involvement. On the other hand, the complication rates of the radical joint resection and immediate obliteration of the chest wall defect with pectoralis flap have been reported even as high as $50 \%{ }^{\left[{ }^{[7]}\right.}$. This aggressive surgery in the acute infection phase can further increase the perioperative morbidity in patients with liver dysfunction associated immunosuppression and coagulopathy. In our opinion, the surgery has to be adapted to the patient condition and estimated perioperative risk, tissue quality and systemic infection control. The favoured surgical management has to reduce the operative trauma in compliance with the traditional principles of the wound management ${ }^{[8]}$. We recommend the NPT as an effective addition for the surgical wound debridement. The NPT application has been widely used in acute, subacute and chronic wounds. It enables better infection control by improving the blood flow, accelerating the tissue granulation and reducing bacterial colonization in the wound $^{[8,9]}$. The accelerated bacterial clearance is, in our opinion, the main advantage in the acute infection phase in patients with compromised liver function. In our patient group the chest wall resection was adapted to the extent of bone destruction, extent of the osteomyelitis and included the hemimanubrium $(n=6)$, first $(n=5)$ and second rib $(n=3)$. Our radical SCJ resections resulted in a large chest wall defect according to classification of Joethy et al, reflecting a regularly wide infection in patients with liver insufficiency ${ }^{[10]}$. Subsequent radical joint resection has been reported adequate for the patients with extended disease ${ }^{[11,12]}$. In our opinion, the adequate assessment of the bone viability and the osteomyelitis extent is of key relevance in the treatment of SCJ infections. The postponed bone resection thanks to NPT allows to better assess the bone viability and to define the resection extent, particularly in severe infections ${ }^{[13]}$.

Chest wall defect coverage with the pedicled muscle or musculocutaneous flap has been the preferred technique. For the complete filling of the residual space, protective coverage of the exposed brachiocephalic vessels and preservation of neurovascular integrity in the upper extremity the pectoral muscle has commonly been accepted ${ }^{[11]}$. Some authors provided the vascularized muscle flap an additional anti-inflammatory effect due to the direct antibiotic delivery to the infection site once the flap is in place ${ }^{[13]}$. The novel technique of the large bone defect obliteration with engineered bone tissue is a challenge in the reconstructive surgery ${ }^{[14]}$.

Extended SCJ infection and associated massive inflammatory process usually affect the ipsilateral chest wall musculature precluding its application as the defect coverage. The transposition of the unimpaired contra- 
lateral pectoralis major muscle has therefore been preferred in our patients. The chest wall reconstruction using the pectoral PMF enabling successful long-term infection control within the SCJ has already been described $^{[6,15,16]}$. In addition to the described technique, other clinically important issues have to be taken into consideration. Firstly, the higher perioperative risk associated with the liver impairment has to be expected. Therefore, staged procedure adapted to the reduced patient status is recommended. Secondly, a wide involvement of the neighbouring structures and mediastinum was present in all our cases. Finally, the aggressive one stage approach with the SCJ resection and simultaneous muscle transposition is associated with higher complication rate and can be replaced by the presented staged strategy.

In conclusion, the staged NPT based surgical therapy of the acute SCJ infections in patients with hepatic impairment is feasible. It helps reduce the high perioperative morbidity, maintaining the principles of wound management. The presence of liver dysfunction and consequent coagulopathy is associated with increased blood product demand and requires a well-balanced interdisciplinary approach.

\section{DECLARATIONS}

\section{Authors' contributions}

Study design: Schreiner W, Horch RE, Sirbu H

Sequence alignment and manuscript drafting: Schreiner W, Dudek W, Trufa DI

Statistical analysis: Schreiner W

Coordination of the study: Horch RE, Sirbu H

Read and approved the final manuscript: all authors

\section{Availability of data and materials}

Results are reported in the manuscript, patient's individual data are not available to the public for the sake of data protection laws.

\section{Financial support and sponsorship

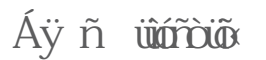

\section{Conflicts of interest}

All authors declared that there are no conflicts of interest.

\section{Ethical approval and consent to participate}

There are no ethical concerns over the study.

\section{Consent for publication}

Not applicable.

\section{Copyright}

(c) The Author(s) 2018.

\section{REFERENCES}

1. Ross JJ, Shamsuddin H. Sternoclavicular septic arthritis. Review of 180 cases. Medicine (Baltimore) 2004;83:139-48.

2. Bakaeen FG, Huh J, Fagan SP, Bellows CF. Surgical treatment of sternoclavicular joint infections in cirrhotic patients. Am J Surg 2008;195:130-3.

3. Kamath PS, Wiener RH, Malinchoc M, Kremers W, Therneau TM, Kosberg CL, D'Amico G, Dickson ER, Kim WR. A model to predict survival in patients with end-stage liver disease. Hepatology 2001;33:464-70.

4. Abu Arab W, Khadragui I, Echavé V, Deshaies A, Sirois C, Sirois M. Surgical management of sternoclavicular joint infection. Eur J Cardiothorac Surg 2011;40:630-5.

5. Guerra C, Spillane LL. Sternoclavicular septic arthritis in a patient with end-stage liver disease. Ann Emerg Med 1996;27:264-6.

6. Song HK, Guy TS, Kaiser LR, Shrager JB. Current presentation and optimal surgical management of sternoclavicular joint infections. Ann Thorac Surg 2002; 73:427-31.

7. Puri V, Meyers BF, Kreisel D, Patterson GA, Crabtree TD, Battafarano RJ, Krupnick AS. Sternoclavicular joint resection: a comparison 
of two surgical approaches. Ann Thorac Surg 2011;91:257-62.

8. Argenta LC, Morykwas MJ. Vacuum-assisted closure: a new method for wound control and treatment: clinical experience. Ann Plast Surg 1997,38:563-7.

9. Carlos GN, Kesler KA, Coleman JJ, Broderick L, Turrentine MW, Brown JW. Aggressive surgical management of sternoclavicular joint infections. J Thorac Cardiovasc Surg 1997;113:242-7.

10. Joethy J, Lim CH, Koong HN, Tan BK. Sternoclavicular joint infection: classification of resection defects and reconstructive algorithm. Arch Plast Surg 2012;39:643-8.

11. Pimpec-Barthel Le F. Editorial comment on: surgical management of sternoclavicular joint infection. Eur J Cardiothorac Surg 2011;40:6345.

12. Landreneau RJ. Comment on: sternoclavicular joint resection: a comparison of two surgical approaches. Ann Thorac Surg 2011;91:261-2.

13. Muesse JI, Blackmon SH, Ellsworth IV WA, Kim MP. Treatment of sternoclavicular joint osteomyelitis with debridement and delayed resection with muscle flap coverage improves outcomes. Surg Res Prac 2014;2014:747315.

14. Kneser U, Schaefer DJ, Polykandriotis E, Horch RE. Tissue engineering of bone: the reconstructive surgeon's point of view. J Cell Mol Med 2006;10:7-19.

15. Haddad M, Maziak DE, Shamji FM. Spontaneous sternoclavicular joint infections. Ann Thorac Surg 2002;74:1225-7.

16. Burkhart HM, Deschamps C, Allen MS, Nichols FC, Miller DL, Pairolero PC. Surgical management of sternoclavicular joint infections. J Thorac Cardiovasc Surg 2003;125:945-9. 